\title{
Friendship and Literacy Through Literature
}

\author{
Annemarie Sullivan Palincsar, \\ Andrea DeBruin Parecki, and Jean C. McPhail
}

The exploratory research reported in this article was designed to determine the processes and outcomes of planning thematic literacy instruction in a holistic and contextualized manner. The work was conducted in an upper-elementary, self-contained setting for students identified as learning disabled. Specifically, the instructional activities included (a) interactive readings from literature on friendship, (b) personal written responses to the literature, (c) supported retellings of the literature, (d) performance related to the literature, and $(e)$ journal writing on the topic of friendship. The outcomes are reported in terms of the use of intertextuality over the course of the 6-week unit, the emergence of theme as a salient feature in literature, and a change in the children's conceptions of friendship. More specific literacy outcomes are captured in case studies of 3 children.

$\mathrm{T}$ his article describes exploratory research involving the use of thematic instruction in an upper-elementary, self-contained special education classroom for students identified as learning disabled. The literature and instructional activities were organized around the theme of friendship, a theme that emerged as a response to the students' concerns about their own abilities to make and keep friends. This research had several purposes, one of which was to examine the development of children's understandings related to friendship in the course of reading and responding to fantasy, realistic fiction, and nonfiction texts about friendship. A second purpose was to determine what an array of activities, broadly conceptualized as responding to literature, would reveal about the students' literacy learning. Supporting these purposes are claims that thematic instruction enables children to form more integrated knowledge bases, leading to richer conceptual under- standings (Lipson, Valencia, Wixson, \& Peters, 1993; Perkins, 1989).

\section{Theoretical Framework}

There are numerous challenges in providing literacy instruction to students identified as learning disabled. Etiology aside, these students may demonstrate a host of difficulties variously characterized as problems of selective attention, metacognitive awareness, strategic engagement, and perspective taking (Englert, Raphael, \& Anderson, 1988; Graham \& Harris, 1992; Williams, Brown, Silverstein, \& de Cani, in press). Perhaps in response to the nature and seriousness of these difficulties, it is not uncommon for instruction in these classrooms to focus on the mechanics of reading and writing, typically in a decontextualized, reductionist manner, which, in turn, constrains the opportunities these learners have to experience reading and writing in holistic and meaning- ful ways (Allington \& McGill-Franzen, 1989; Needels \& Knapp, 1994; Poplin, 1988; Rueda, 1990).

Our search for an alterative conception of literacy instruction with special education students has been informed by the tenets of the sociohistorical school represented principally in the work of Soviet psychologists. One of the most important achievements of Soviet psychology in the late 1930s was its introduction of the concept of activity into research on the genesis and development of the mind and consciousness. Leont'ev (cited in El'konin, 1972) wrote, "Thus, in studying the mental development of the child we must proceed from the development of his activity as that activity arises from the given, concrete conditions of the child's life"(p. 226). In other words, mental processes are dependent upon the motives and tasks of the activity in which they are involved; they are determined by the place they occupy in the structure of the activity (the action or operation). Two sets of activities are proposed within activity theory: those that are related to learning the objectives, motives, and norms of human relations, and those that shape the intellectual powers of the individual.

Activity theorists argued for the need to overcome the dichotomy between the development of the needmotivational aspects and the intellectual and cognitive aspects of the per- 
sonality. Activity theorists further proposed that certain activities are leading, or dominant, in the development of the individual. For the young child of preschool age, the lead activity is play. For the child entering school, instruction becomes the dominant activity; and the lead activity of adolescence is the activity of social contact: the building of relationships with friends on the basis of moral and ethical norms (Vygotsky, 1978).

One aim of our work was to create settings in which these two leading activities, instruction and social contact, would assume prominence. Hence, while we were conscientious about exploring story structure with students as a tool for aiding text comprehension, we were equally attentive to the possibilities each story provided for connecting with students' experiences and emerging notions of friendship. Just as the students were encouraged to generate predictions about the story based on what they knew about the characters, or based on what they knew about that particular text genre, so were they encouraged to make predictions based upon the feelings of the characters, or their projected feelings. In addition to writing about the theme of each story, students were asked to indicate how each story enhanced their own understanding of, and experiences with, friendship. In this manner we hoped to achieve an interplay between the two leading activities that mark this time of development and learning.

Additional tenets of the sociohistorical perspective (as represented in the works of Leont'ev, 1932; Luria, 1976; and Vygotsky, 1978) suggest that literacy learning is best understood and approached as cultural practice; the cognitive processes related to literacy are best acquired in holistic, contextualized activity; and literacy processes are constituted in social interactions with others (Englert \& Palincsar, 1991). Hence, the literacy activities in the research we report on here were conceptualized as social and collaborative enterprises. For example, to situate literacy learning in a holistic and contextualized manner, retellings were conducted for the purpose of planning how one would tell the story to others who were unfamiliar with it. Preparing a script that would capture the story (where the story was retold using puppetry or a play) required considerable collaboration and negotiation among the members of the class.

\section{Translating Theory Into Practice}

In this next section, we will describe the implementation and outcomes of an instructional intervention that was informed by the theoretical principles described above. We begin by describing the special education classroom serving students identified as learning disabled in which this research was conducted; then proceed to describe the instructional activities, the questions that guided our study of how the children responded to the intervention, and a selection of outcomes.

\section{Context}

The school in which this class was located serves a population of working poor families, a number of whom had been employed in an automotive manufacturing plant that had recently closed. The 10 children in this class were between the ages of 8 and 12 and were considered to be third and fourth graders. Seven of the children were from racial-minority families; five of the children were girls. All but one child spoke English as his or her first language. Each child had been in a self-contained classroom for children identified as learning disabled for at least 2 years at the time of this project. Their reading and writing achievement was considerably below grade level, with reading achievement assessed to range from mid-first to mid-second grade, based on the results of the Qualitative Reading Inventory
(Leslie \& Caldwell, 1990). Their writing achievement was also significantly below grade level; $70 \%$ of the children used preconventional forms of writing, whereas the remaining children wrote in conventional forms. The literacy program in place in this classroom included daily guided, oral reading from a children's anthology and journal writing. During journal writing, the students were encouraged to make entries of their own choosing.

We had the good fortune to have spent the previous year and a half in this classroom, observing the students' responses to literacy instruction, before launching the friendship unit. Therefore, we were quite familiar with the students and the curriculum. As we studied the journal writing in this classroom the previous year, we were struck by the fact that the range of purposes, and the kinds, of writing in which the children engaged was somewhat constrained, despite the fact that the teacher was careful to include journal feedback sessions and to encourage more diverse uses of writing through the questions she raised in each student's journal. Furthermore, although the teacher used a children's anthology, only 2 of the 10 children were able to identify a favorite story during interviews that were administered prior to beginning the unit of instruction. Our decision to investigate the use of thematic instruction was prompted, in part, by the considerable evidence we had gathered that although there were opportunities that we associate with a rich literacy environment, these children had not embraced those opportunities, nor did they demonstrate anticipated gains in literacy learning.

Hence, the instruction was designed with multiple goals in mind, including increasing interest, engagement, and achievement in reading and writing. We will first describe the broad strokes of the curriculum and then detail the enactment of it, referring to the principles that informed the instruction. 


\section{Instructional Intervention}

The instructional activities included (a) interactive readings from literature on friendship, (b) personal written responses to the literature, (c) supported retellings of the literature for the purpose of preparing a performance to share the literature with others, (d) performance related to the literature, and (e) journal writing on the topic of friendship.

The selected literature included fantasy, realistic fiction, and nonfictionall of which addressed different facets of friendship (see Note). Our goal was for the students to acquire increased understanding of, and shared experiences with, the theme of friendship. The texts were also selected because they represented an array of text structures; for example, while each story contained typical story elements (characters and setting), they also were organized using cause and effect, problem/solution, and sequences of events.

The specific instructional activities included the following: In preparation for reading each story, the students generated predictions based upon the title, the cover illustrations, and their developing understandings of friendship. This preparation was followed by an interactive reading of the story (the teacher read the text aloud as children followed along), during which the students were encouraged to comment on the developments in the text and to relate the story not only to their personal experiences as friends, but also with the other stories they had read in the friendship series. The teacher scaffolded these discussions by initially modeling interactions with the story, for example, commenting on how the story reminded her of a friendship she enjoyed, how the story suggested a different aspect of friendship, or how the friendship depicted in one story compared with that in another. In each case, the teacher was careful to justify her statement by drawing upon the literature or personal experiences. Over time, the teacher made fewer of these comments and instead would pause opportunistically in the reading, to give the students the chance to comment or raise issues.

The interactive reading of the text was followed by each student generating a personal response to the piece of literature; the children were encouraged to write about the ways in which the story added to or changed their ideas about friendship. These responses were for personal use and were written using whatever forms of writing the students had in their repertoires, with the teacher providing such support as holding ideas in memory for the child, reminding the child where the spellings could be found in environmental print, and helping the child sound out words that were phonetically regular.

The day after the interactive reading and personal response to the story, the group engaged in a teacher-led retelling of the story. The retelling activity was for the purpose of teaching the students to make use of the story structure to support their recall and retelling of the story. For example, the students always began their retellings by identifying the characters, setting (where appropriate), and problem in the story. They then completed, as a group, a graphic that best depicted the events in the story. Through discussion, the students determined the key ideas or events in the story to be captured in the retelling. Although these retellings were initially heavily directed and led by the teacher, over the course of the 6-week unit of study the students required less and less teacher assistance in generating their retellings.

Following the retelling, the children prepared a script for a performance of the story; the performances varied from a puppet show to a dramatic reenactment of the story. In some cases, the class drew a mural depicting the events and narrated the story, with their narrations assisted by the mural. The purpose of this activity was to provide the students an array of opportunities for making the story their own. Converting the retellings to scripts provided the students with multiple opportunities to determine what was most salient about the stories and how to best communicate those ideas in their own words. In addition to writing in response to the literature, the students also maintained a "friendship journal," for the purpose of reflecting on themselves as friends and on what they valued in friendships. These writings were more extensive than the brief responses made following the stories, and were read aloud to the class for the purpose of soliciting feedback from the other members about their writing and their ideas. To draw the 6-week, six-story unit to a close, the class formed a critics' circle. In preparation for critics' circle, the children wrote their opinions of each of the six stories read, presented their critiques, and then voted for their favorite story, to which they awarded the Class Newbery Award.

\section{Results}

In keeping with the exploratory nature of this research, we will address the outcomes by describing a number of observations that emerged in the course of studying the pre- and postinterviews, the writing that the children engaged in following the reading, and transcripts of all the group interactions (e.g., the reading, the retellings in preparation for the performances, the performances themselves). Guiding our observations was the following set of questions:

1. What are the opportunities for students with learning disabilities to learn about reading, writing, and themselves in the course of reading and responding to a series of stories related to the theme of friendship?

2. How do the students make cumulative reference across stories? 
3. Given different kinds of opportunities to generate responses to literature, what do these children reveal about themselves, their responses to literature, and their literacy skills?

Guided by these questions, we made a number of observations. Given the nature of our work, we will first report observations using the group as the unit of analysis; this will be followed by the cases of 3 children.

\section{Class Responses to the Unit}

Use of Intertextuality. Hartman (1991), among others, has observed that good readers generate interconnections, or links, between texts, which result in webs of meaning, providing the reader with a multidimensional network of textual resources. Indeed, as we examined the transcripts of student conversation in the course of the interactive readings, we noticed a number of occasions when the children drew upon one text to help them bring meaning to a second. For example, having read (the previous week) the story of a unicorn that gives up her horn to a friend (a sheep who longs to have a horn), Carolyn begins to anticipate a similar scenario for a story entitled "A Place for Everyone" a story about two elephants, one of whom has pink ears. "I think the big elephant with pink ears isn't happy because her ears aren't gray, but they might be gray at the end of the story. I think the little one is gonna give him his ears, and the little one will disappear." In this instance, Carolyn has transposed two features from the previous story onto this story-the sharing of a coveted possession, and the price of this sacrifice (the unicorn in the previous story does indeed disappear upon sharing her horn).

We are aware of very little work attempting to determine how students with comprehension difficulties respond across multiple texts; yet, the instances that we observed of children making resourceful use of inter- textuality suggests that intertextuality may provide both a tool for enhancing the achievement of these children and a richer picture of how children with comprehension difficulties approach text.

The Emergence of Theme as a Salient Feature of Literature. The question of how children with learning difficulties draw generalizations from literature for the purposes of moving beyond the plot to identify themes, or "underlying ideas that tie the plot, characters, and setting together into a meaningful whole" (Norton, 1991, p. 98), was of considerable interest to us. In part, this interest arose from the difficulties that researchers have reported in attempts to teach theme to children identified as learning disabled (e.g., Dimino, Gersen, Carnine, \& Blake, 1990; Guerney, Gersten, Dimino, \& Carnine, 1990). In addition, we were mindful of the admonitions of Williams et al. (in press), who have speculated that students with learning disabilities have a lot to lose, rather than gain, from curriculum reforms that move us toward holistic, integrated curricula and instruction and away from highly structured, direct instruction. We decided in advance of beginning the unit that we would not provide direct instruction relative to the theme of friendship but, rather, would use the literature in an opportunistic manner, providing multiple occasions for the teacher and children to comment on and compare what they learned about friendship across stories.

The clearest evidence regarding the development of individual children's notions of the theme across the stories arises from the writing in which the children engaged immediately following the reading of the story. It is important to remember that they were encouraged to write about the ways in which the story added to or changed their ideas about friendship. As we examined the writings across time, we were interested to note that, with few exceptions, the initial writings of the children depicted events in the story. For example, when responding to the first story, 7 of the 8 children for whom we have data (data are missing for 2 children due to absences) recorded events in the story (e.g., "They play and run together." "He wanted to give the horn back to have his friend back."). One child made an entry that might be viewed as thematic: "Friendship is love." With the second story, we see several other children responding in a thematic fashion (e.g., "Friends help each other." "Friends are sad when they are not together."). Toward the end of the unit, 7 of the 10 children were consistently writing about the story in reference to a theme of friendship (e.g., "Friends stand up for each other." "Race doesn't matter in friends."). Furthermore, we were interested to note that in the groupgenerated retellings of the stories (which followed the independent writing), the children consistently punctuated the retelling with a thematic statement. This interested us because, although friendship was central to these stories, the ideas presented about friendship were implicit, and, certainly, thematic statements were not a device used to conclude any of the stories themselves.

Clearly, any conclusions about these children's ability to identify and build upon themes in the context of holistic instruction must be tempered by the acknowledgment that there are themes in narrative literature that vary in complexity, and that the theme of friendship as presented across these stories may be, in comparison, quite simple. Nevertheless, given the difficulties that researchers have reported in attempts to teach theme, we are intrigued by the emergence of theme in these children's writing, and in their efforts to capture what they regarded as important in the stories to share with others who are unfamiliar with them.

Evidence of Change in Children's Conceptions of Friendship. Data to address this outcome are derived from 
the pre- and postinterviews, as well as from the journal writings and discussions that were held in the context of the friendship unit. In the pre- and postinterviews the children were asked to identify some of their friends, discuss why they called them their friends, describe how they showed them that they were friends, and discuss what made a friend really special.

There is a fairly comprehensive developmental literature describing the transformation of children's conceptual understandings regarding friendship from childhood to adolescence. Whereas young children (10 years old and younger) principally describe friends in external and behavioral terms (Bigelow \& LaGaipa, 1980; Smollar \& Youniss, 1982), older children's descriptions reflect more psychological depth (Furman \& Bierman, 1984; Youniss \& Volpe, 1978). We were interested to note that in the context of this 7-week unit, two outcomes were suggested by the responses to the interview questions, both of which speak to the development of a richer sense of friendship over time. First, across all of the children, the number of descriptors they used in responding to the friendship questions during the preassessment numbered 23 . This is in contrast to the 88 descriptors provided during the postassessment interview. The number of descriptors in the preinterview ranged from 1 to 6 and averaged 3 per child; the number of descriptors in the postinterview ranged from 4 to 15 and averaged 7.5 per child. In addition, whereas the majority of responses on both the preand postassessments referred to the external, or sharing, activities that young children typically use to characterize friendship (e.g., "They're nice." "I play with them." "We go to each other's house and ride bikes."), postassessments showed a $16 \%$ increase in responses reflecting conceptions of friendship that were psychological in nature and reflected the intimacy, support, and reciprocity that is true of friends (e.g., "They help you and you help them." "Trust each other." "Standing up for each other.").

Additional group outcomes included the following: At the conclusion of this unit of study, each child successfully identified and retold a favorite story, using all of the story elements. Although they were not prompted to do so, they each retold one of the friendship stories. Recall that only 2 of the 10 children identified a favorite story in the preinterview setting. The sheer amount of writing in which the children engaged increased significantly; this is illustrated in the cases that follow. Finally, interest in the stories themselves prompted the children to independently engage in repeated independent readings.

\section{Case Studies: Three Children}

To further illustrate the children's development of understandings about friendship and their uses of writing across the unit, we present the cases of 3 students. Two girls and a boy, all 10 years of age and all African American, were chosen to represent the class. These children were selected on the basis of having varying literacy levels, as well as differing responses to the activities within this unit. After introducing each of the children separately, we will examine their oral responses to pre- and postinterview questions, a sample of their written responses to a question about friendship, and their selection of themes for several of the stories read.

Tamika was the highest achieving student in this class. Her teacher reported that her reading and writing performances were actually quite close to her grade level, although on formal reading measures her reading was assessed to be equivalent to that of a child at the end of second grade. She participated regularly in class discussions and activities.

Jay was a quiet child, somewhat withdrawn in comparison to the other students. His reading and writing were assessed as comparable to those of a child beginning second grade. Al- though he struggled with both his reading and his writing, he readily participated when the activity was of interest to him.

Tamara was a child whose attitude and attentiveness to the unit fluctuated daily; moody and uncooperative one day, she could be attentive and engaged the next. Tamara's reading level was assessed to be comparable to that of a child at the end of first grade, and her difficulty with writing resulted in very sparse written responses.

As described earlier, after each initial interactive reading of a story, the children were asked to generate a personal response in writing that addressed the ways in which the story added to or changed their ideas about friendship. This writing was done on index cards and was intended to be focused and brief. We have suggested that over time, the children's decisions regarding what to write became more focused on the themes of friendship, and also become more elaborate and complex. Using our case-study children, we shall provide examples of this development.

The first story, Morgan and Yew, concerned the unicorn who shared its horn with the sheep. Tamika's responses to the friendship issue in this story was "you can be yourself," whereas Jay wrote, "They are friends and they play games." Tamara wrote, "They was running." Tamika addressed the overarching theme of the story, Jay related his ideas to the overall theme of friendship, and Tamara did neither. Instead, she concentrated on one of the primary activities that took place in the story (the animals did a lot of running).

The fourth and fifth stories in the unit featured human characters, as opposed to animals. One, Jamaica TagAlong, depicted the story of a young girl who pesters her brother by tagging along. One day, as she is playing, she is pestered by a younger child who wants to join her. Finding herself sounding much like her brother as she rebukes the younger child, she relents 
and invites the younger child to join her. The next story, Teammates, is a piece of historical nonfiction that relates the friendship of Jackie Robinson and Pee Wee Reese, whose friendship persisted in a climate of racism.

In response to Teammates, Tamika wrote, "Friendship is when you stand up for someone especially someone in that time." When asked what "that time" meant, Tamika said she was referring to a time when White and Black people did not get along and often were not friends. She said it took a special kind of person to do what Pee Wee had done-someone who was not afraid to stand up for a friend when times were like that. She added that being a friend was not always easy. Jay was hopeful in his response; he wrote, "In those days, people did not like White and Black. Now people like White and Black." As he read his response to the class, he added that there were children of all colors in the school and in his neighborhood, and they were friends, so things had changed. With the story of Jamaica Tag-Along, Tamara, after focusing exclusively on events and actions in the first three stories, now wrote about her feelings as she read the story: "I like when she be sad cause I be sad too." She added to her response a note regarding friendship: "Age doesn't matter."

The last story of the unit was Elizabeth and Larry. This is a funny and poignant story about a woman and alligator who befriend one another and experience considerable difficulty adjusting to one another's worldsculminating in Elizabeth joining Larry in his world when the ridicule he experienced in her world simply becomes too much for him. There was animated discussion during the initial reading, and when asked to fill out their cards, the children did so eagerly. Tamika wrote, "I thought it was sad that they threw food at Larry because he was different. Larry helps out around the house." In this response, she speaks to the problem posed by Larry's differentness and comments on one attribute of friends, their helpfulness. Jay wrote, "They were friends. They cared about each other. They could not be apart." With this response, he summarized the special qualities he associated with friendship. Finally, Tamara, continuing to move beyond simply the action of the story, wrote, "They was happy because they was friends."

The children's immediate responses to individual stories provided but one way to trace their understandings of the theme of friendship. After reading and discussing the first three stories, the class began entries to their "friendship journals," describing, for example, their special friends. (See Figure 1 for Tamika's engaging response in her first journal entry.)

Jay's first entry in the friendship journal resulted in more writing than he had ever generated on a single occasion in class. As he read his entry, the source of his inspiration became clear (see Figure 2). In the journalsharing session that followed, the class listened nervously as Jay read his entry. The teacher commented that this was the first time that Jay had mentioned in class the accidental drowning of his father, an event that had occurred over a year ago.

In the second of Tamara's friendship journal entries, we read shades of the message she derived from Teammates. Her entry is given in Figure 3. This entry, which is more than Tamara had written since the unit began, indicates the connection she drew from the story to events in her own life: Friends stick up for each other, as she had done for her cousin.

At the close of the friendship unit, before doing our postinterviews, we asked the children to critique the books we had read and vote for the one they

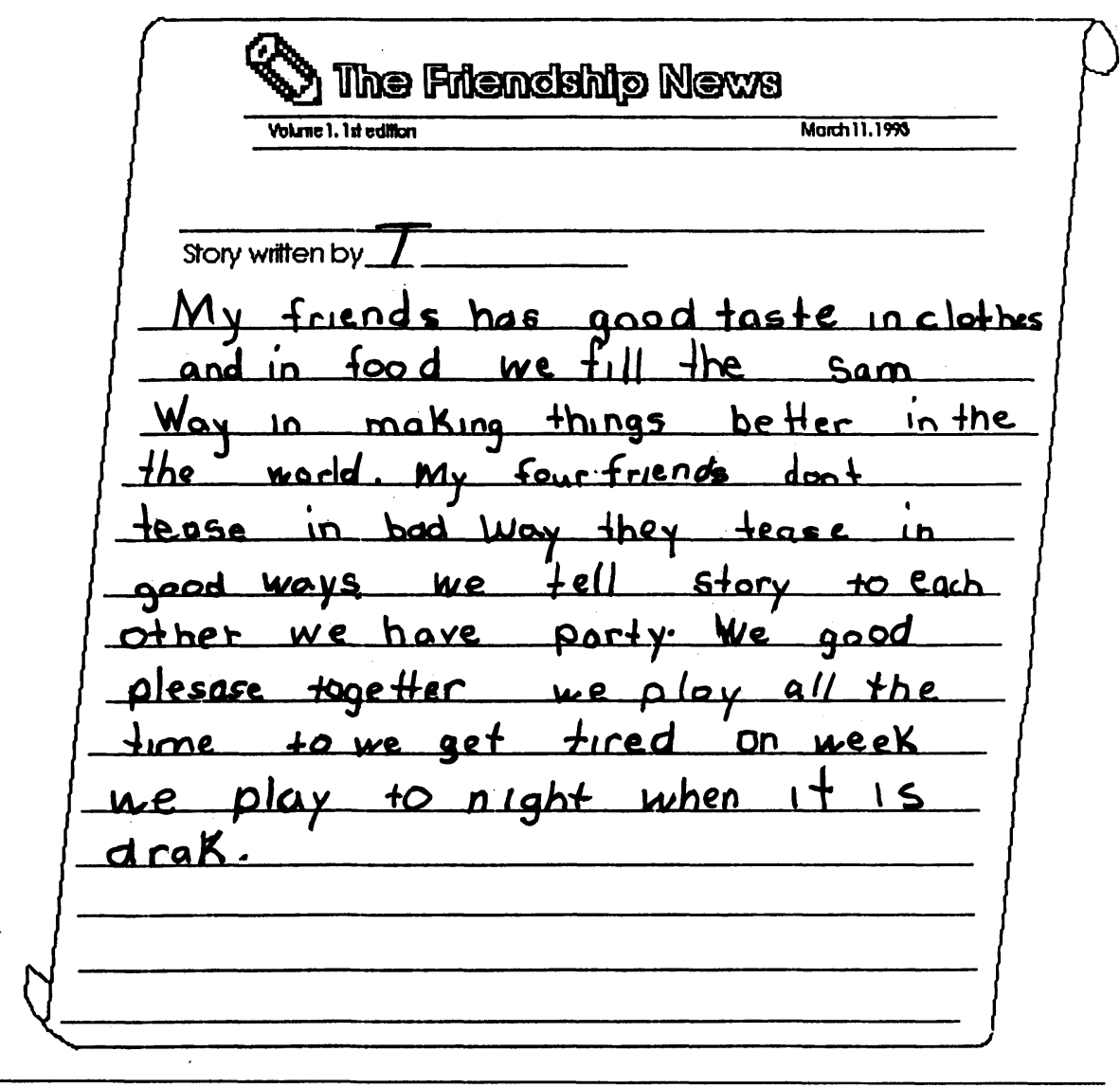

FIGURE 1. Tamika's journal entry. 
liked best and wished to award the class Newbery. This activity was called "Critics' Circle" and was compared to the process critics went through before deciding which children's books would win an award, such as the Caldecott. Although Elizabeth and Larry won the award hands down because it was funny, Tamika insisted on explaining why Teammates was her choice. She wrote, and then read to the class, "I like it because someone like Jackie Robinson, had got a friend. Jackie was different. He was a different color than his other teammates." Pointing to the bulletin board with pictures of Martin Luther King, Jr., and Rosa Parks, she added that Jackie and Pee Wee belonged with the historical figures depicted there.

As a final assessment of what the children had learned about both the theme of friendship and their emerging notions of story, we conducted the postinterviews described earlier. Tamika, who in the preinterview indicated that "friends were kind and friendly, but some were mean," and they "lik[ed] to sleep at each other's houses," now provided us with an elaborate list of what a friend is and does. She said, "Friends stand up for each other. They have good times together. Friends should be able to be themselves. Friends shouldn't fight. Friends spend time together, play and go places." In response to the probe concerning what makes a story a story, Tamika, in the preinterview, responded, "Good scenes" and a "good ending." During the postinterview, she elaborated that a story has "a name, something that happens, has why the book was written, someone who wrote it, characters."

Like Tamara, Jay also indicated deeper understandings of friendship as well as stories. During the preinterview, Jay described friends as "people who play games together, and help each other when they are in trouble." In the postinterview he suggested, "Friends care about each other. Friends stand up for each other.

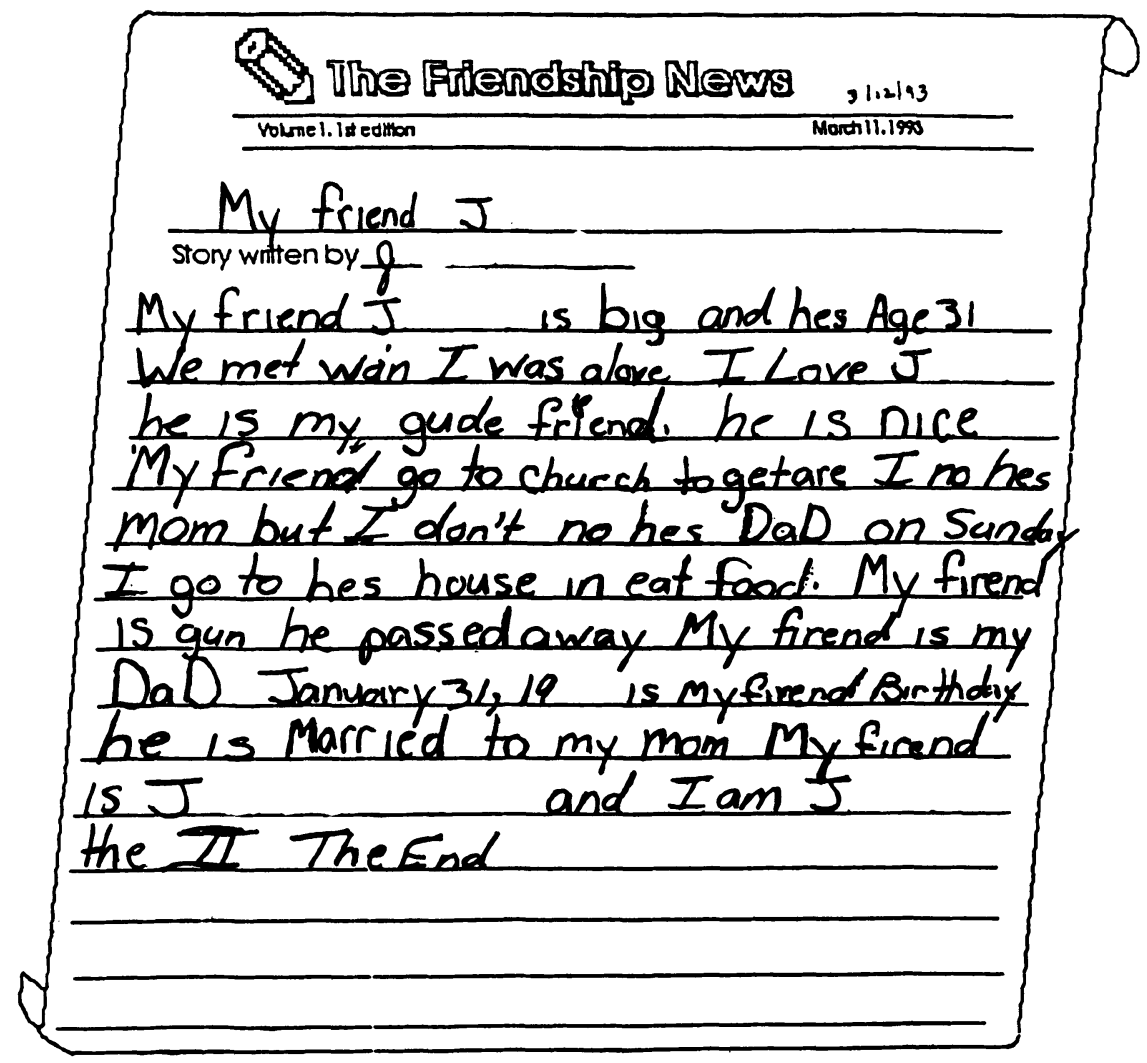

FIGURE 2. Jay's journal entry.

Friends can be different from each other. Friends are funny. Friends share. Friends spend time with each other. Friends help each other." His description of a story changed from "when you like it and it tells about something" to "a story is a story when it has a title, setting, characters, and tells you something."

Finally, Tamara, who at the start of this unit had said friends were friends because "they play together," in the postinterview responded, "Friends are nice. Friends help each other. Friends like each other. Friends do things for each other. Friends do stuff together."

\section{Conclusion}

This research was conducted for the purpose of exploring the design and implementation of instruction, guided by the tenets derived from a sociocultural perspective. In the various activity settings that we have described, the children read and wrote for a broad range of purposes, including indicating their understanding of the stories, expressing their own opinions, creatively representing the stories to others, and reflecting on their own beliefs about friendship. They experienced reading and writing in holistic and integrated ways. They assisted each other during activities, sharing their expertise and knowledge. Finally, from a developmental standpoint, the instruction began with the children, both in terms of their concerns about friendship and in terms of their current literacy levels. These would appear to be useful guidelines in planning meaningful instruction for students identified as learning disabledinstruction that is adapted to their 


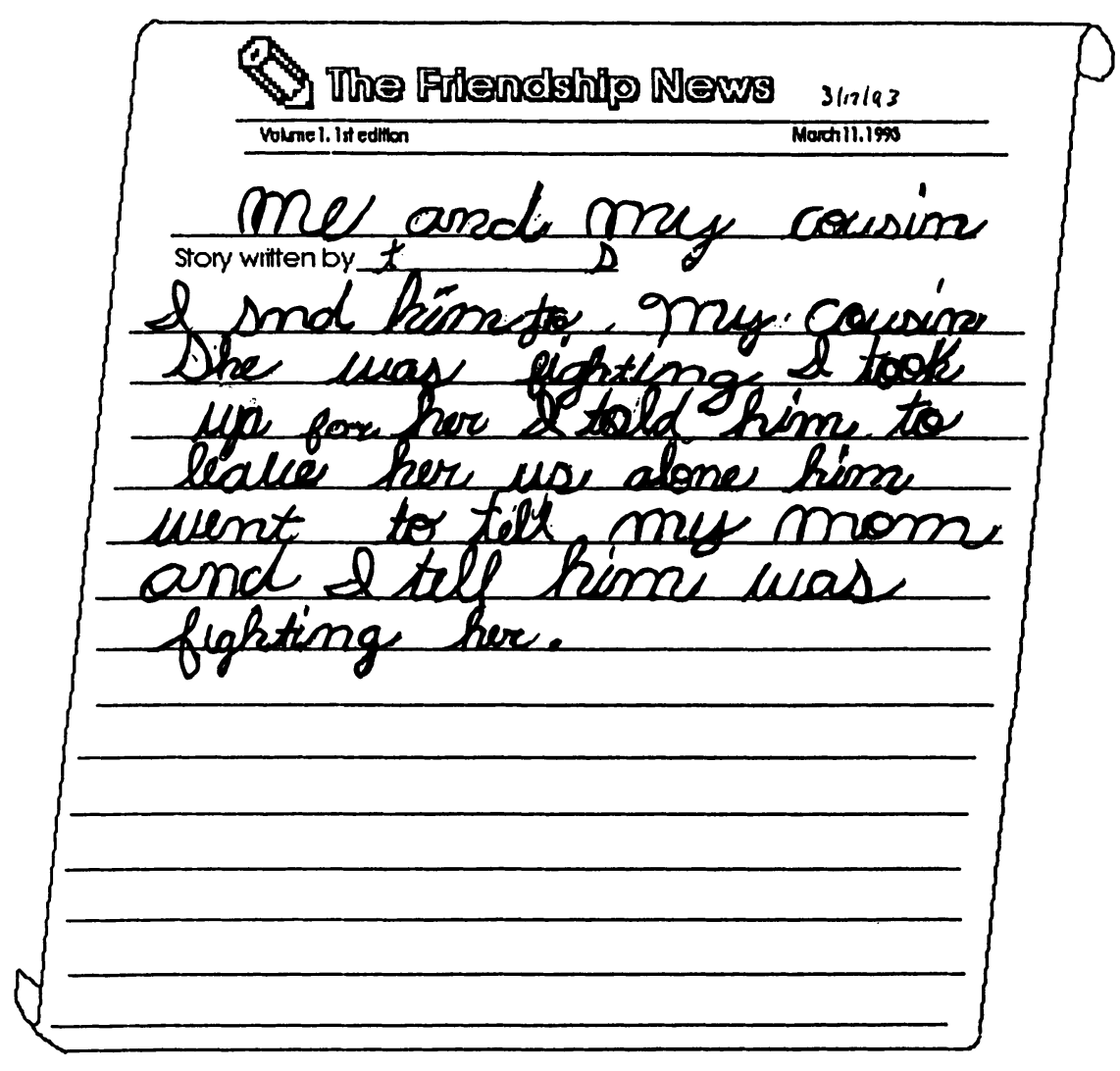

FIGURE 3. Tamara's journal entry.

special needs without compromising the important social and communicative goals of literacy.

\section{ABOUT THE AUTHORS}

Annemarie Sullivan Palincsar is the Jean and Charles Walgreen, Jr., Professor of Literacy in the School of Education at the University of Michigan. In addition to preparing teachers to work in diverse classrooms, she conducts instructional research on guidedinquiry learning and literacy development in special education contexts. Andrea DeBruin Parecki is a doctoral candidate in the combined program in education and psychology at the University of Michigan. She is especially interested in the educational experiences of minority-culture children. Jean C. McPhail is on the faculty of the literacy, language, and learning disabilities program in educational studies in the School of Education at the University of Michigan. She specializes in studying the influence of methodology on notions

of school learning and context. Address 49109 .

\section{AUTHORS' NOTES} ment of Education. conduct this research with her students.

\section{NOTE}

Tag-Along, by Juanita Havill; Teammates, by Peter Golenbock; and Elizabeth and Larry, by Marilyn Sadler.

\section{REFERENCES}

Allington, R. L., \& McGill-Franzen, A. (1989). School response to reading failure: Instruction for Chapter I and special education students in grades two, four, and eight. Elementary School Journal, 89, 529-542.

Bigelow, B. J., \& LaGaipa, J. J. (1980). The development of friendship values and choices. In H. C. Foot, A. J. Chapman, \& J. R. Smith (Eds.), Friendship and social relations in children (pp. 15-44). New York: Wiley.

Cosgrove, S. (1982). Morgan and Yew. Los Angeles: Price-Stern-Sloan.

Dimino, J., Gersten, R., Carnine, D., \& Blake G. (1990). Story grammar: An approach for promoting at-risk secondary students comprehension of literature. Elementary School Journal, 91, 19-32.

El'konin, D. B. (1972). Toward the problem of stages in the mental development of the child. Soviet Psychology, 4, 225251.

Englert, C. S., \& Palincsar, A.S. (1991). Reconsidering instructional research in literacy from a sociocultural perspective. Learning Disabilities Research and Practice, 6, 225-229.

Englert, C. S., Raphael, T. E., \& Anderson, L. M. (1988). Students' metacognitive knowledge about informational texts. Learning Disability Quarterly, 11, 18-46. Annemarie S. Palincsar, Educational Studies, University of Michigan, 4204 C School of Education, 610 East University, Ann Arbor, MI

1. This research was supported in part by a grant from the U.S. Department of Education, Office of Special Education Programs (No. H023C90076). The opinions and statements in this article are those of the authors and in no way represent positions of the U.S. Depart-

2. The authors express their gratitude to Ms. Carol Brozo, who gave us the opportunity to

The literature used in this unit includes the following: Morgan and Yew, by Stephen Cosgrove; A Place for Everyone, by Barbara Resch; Amos and Boris, by William Steig; Jamaica
Furman, W., \& Bierman, K. L. (1984). Childrens' conceptions of friendship: A multimethod study of developmental changes. Developmental Psychology, 20, 925-931.

Golenbock, P. (1992). Teammates. New York: Macmillan.

Graham, S., \& Harris, K. (1992). Teaching writing strategies to students with learning disorders: Issues and recommendations. In L. Meltzer (Ed.), Cognitive, linguistic, and developmental perspectives on learning disorders. Boston: College-Hill.

Guerney, D., Gersten, R., Dimino, J., \& Carnine, D. (1990). Story grammar: Effective literature instruction for high school students with learning disabilities. Journal of Learning Disabilities, 23, 335-343.

Hartman, D. K. (1991). The intertextual links of readers using multiple passages: A postmodern/semiotic/cognitive view

(Continued on p. 522) 